\title{
ARTIGOS
}

\section{RELAÇÕES ENTRE JULGAMENTO \\ MORAL, RACISMO E EMPATIA \\ EM CRIANÇAS}

DANIELA SANTOS BEZERRA'

FRANCYELLY OLIVEIRA PEREIRA DOS SANTOS"

SHEYLA CHRISTINE SANTOS FERNANDES"I

\section{RESUMO}

O presente estudo objetivou analisar as relações entre julgamento moral, racismo e empatia em crianças. Participaram 76 estudantes de Maceió, entre 7 e 12 anos $(M=9,71 ; D P=1,65)$. Utilizou-se um dilema moral, com duas versões de desfecho, para análise do julgamento moral em duas dimensões: generosidade e justiça. Para empatia, utilizou-se a Escala de Empatia para Crianças e Adolescentes (EECA). Por fim, utilizou-se uma história sobre preconceito racial. Os resultados apresentaram maior adesão das crianças à generosidade e à empatia, com baixa adesão ao racismo. As dimensões generosidade e justiça se apresentaram inversamente correlacionadas, havendo também correlação inversa entre um dos fatores de empatia e racismo.

CRIANÇAS • RAÇA • PRECONCEITO • EMPATIA

\section{RELATIONS BETWEEN MORAL JUDGMENT, RACISM AND EMPATHY IN CHILDREN}

\section{ABSTRACT}

This study aimed to analyze the relations between moral judgment, racism and empathy in children. Participants included 76 students from Maceió city, Brazil,

Universidade Federal de Alagoas, Maceió (AL), Brasil; dani.dsb@hotmail.com

Universidade Federal de Alagoas, Maceió (AL), Brasil; oliveirafrancyelly@gmail.com

Universidade Federal de Alagoas, Maceió (AL), Brasil: sheylacsfernandes@msn.com aged 7 to 12 years $(M=9.71, S D=1.65)$. A moral dilemma was used, with two versions of the outcome, to analyze moral judgment in two dimensions: generosity and justice. For empathy, the Empathy Scale for Children and Adolescents (ESCA) was used. Finally, a story about racial prejudice was used. The results showed greater children's adherence to generosity and empathy, with low adherence to racism. The dimensions of generosity and justice were inversely correlated, and there was also inverse correlation between one of the empathy factors and racism. 


\section{RAPPORTS ENTRE JUGEMENT MORAL, RACISME ET EMPATHIE CHEZ LES ENFANTS}

RÉSUMÉ

Cet article analyse les rapports entre le jugement moral, le racisme et l'empathie chez les enfants. 76 élèves, entre 7 et 12 ans $(M=9,71 ; D P=1,65)$ de la ville de Maceió, ont participé à l'étude. Un dilemme moral proposant deux issues possibles a été utilisé pour analyser le jugement moral sur deux dimensions : celles de la génerosité et de la justice. L'empathie a été mesurée à partir de l'échelle d'empathie pour enfants et adolescents (EEE). Finalement on a eu recours à une historie sur le prejugé racial. Les résultats ont montré une forte adhésion des enfants à la générosité et 'a l'empathie et une faible adherence au racisme. Les dimensions générosité et justice apparaissent inversement corrélées et il existe aussi une corrélation inverse entre un des facteurs de l'empathie et le racisme.

ENFANTS • RACE • PREJUGÉ • EMPATHIE

RESUMEN

El presente estudio tuvo el objetivo de analizar las relaciones entre el juicio moral, el racismo y la empatía en los niños. Participaron 76 estudiantes de Maceió, con edades entre los 7 y los 12 años $(M=9,71, D P=1,65)$. Se utilizó un dilema moral, con dos versiones de desenlace, para analizar el juicio moral en dos dimensiones: generosidad y justicia. Para la empatía, se utilizó la Escala de Empatía para Niños y Adolescentes (EECA). Por último, se hizo uso de una historia sobre el prejuicio racial. Los resultados presentaron mayor adhesión de los niños a la generosidad y la empatía, con baja adhesión al racismo. Las dimensiones de generosidad y justicia se presentaron inversamente correlacionadas, así como también hubo una correlación inversa entre uno de los factores de empatía y el racismo. 


\section{PRECONCEITO E RACISMO}

MA MATÉRIA PUBLICAdA PELO PORTAL dE NOtícIAS ONLINE G1 DESTACOU O CASO de uma menina de 10 anos que sofreu com comentários racistas de algumas colegas. O caso aconteceu em uma escola de Rio Branco (AC). Segundo a tia da criança, ela teria sido chamada de "preta imunda e suja” por diversas vezes e a direção da escola teria tratado o caso como "besteira”. Ainda de acordo com a tia, após sofrer as ofensas, a criança teria ficado muito abalada e chegado em casa chorando. Antes do ocorrido, ela era alegre e sorridente, mas passou a apresentar mudanças em seu comportamento (RODRIGUES, 2015).

De modo semelhante, uma matéria do jornal Folha de São Paulo aponta para a prevalência de racismo e preconceito entre crianças, com destaque para um caso que aconteceu em um colégio de Campo Grande (MS). Luís (nome fictício), garoto negro de apenas 5 anos, era alvo de piadas dos colegas: "Estou comendo o Luís, estou comendo o Luís!". Frase repetida sempre que um deles comia um chocolate. Além disso, o menino era rejeitado pelos grupos de sua classe e ficava sozinho na hora das brincadeiras. A reportagem ainda destaca que pais, psicólogos, pediatras e professores afirmam que casos como o de Luís acontecem com frequência. No entanto, no Brasil, são raros os estudos voltados à temática da intolerância entre crianças (MATTOS, 2007).

O preconceito consiste em uma atitude hostil a um indivíduo, porque este pertence a determinado grupo desprestigiado socialmente 
(ALLPORT, 1954). Apesar da condenação às expressões mais flagrantes de intolerância intergrupal, esta não vem diminuindo. Mudanças sociais importantes emergiram após o período da Segunda Guerra Mundial, como a divulgação das consequências do nazismo na Europa, a adoção da Declaração Universal dos Direitos Humanos e a luta pelos direitos civis nos Estados Unidos da América (EUA), apresentando forte influência no processo de mudança de configuração do preconceito. Consequentemente, crenças e comportamentos preconceituosos e racistas sofreram uma alteração em seus modos de expressão (FERNANDES, 2011). Diversos autores consideram a permanência de sentimentos e atitudes preconceituosas que não contestam explicitamente as atuais normas sociais antirracistas (KATZ; WACKENHUT; HASS, 1986; MCCONAHAY, 1986; MEERTENS; PETTIGREW, 1999; PETTIGREW; MEERTENS, 1995; VALA; BRITO; LOPES, 1999).

As sociedades modernas desenvolveram formas de limitar as práticas discriminatórias fundamentadas nas diferenças de raça, levando as pessoas a se adaptarem. Desse modo, a diminuição das expressões do racismo seria algo mais simulado do que real, tendo em vista a persistência no interior das consciências dos indivíduos de atitudes preconceituosas que não desafiam claramente as atuais normas antidiscriminatórias. A discriminação explícita, que implica crenças na inferioridade do grupo discriminado e rejeição de proximidade com os seus membros, está sendo substituída por formas mais sutis de discriminação (CAMINO et al., 2001).

Alguns estudos apontam que as crianças, assim como os adultos, apresentam crenças e comportamentos intolerantes frente a membros de grupos minoritários, no entanto, por volta dos sete anos de idade, haveria uma diminuição em suas formas de expressão. Essa diminuição do preconceito, trazida pela abordagem cognitiva do desenvolvimento, poderia ser explicada por conta da aquisição de novas estruturas cognitivas, além do amadurecimento das estruturas já existentes (ABOUD, 1988; DOYLE; ABOUD, 1995).

Ao contrário da perspectiva da abordagem cognitiva do desenvolvimento do preconceito na infância, há autores que salientam que os novos modos de expressão do preconceito podem ser resultantes da introjeção das normas sociais antirracistas e que o contexto de resposta em que o sujeito se encontra pode ser determinante de uma expressão mais velada ou mais aberta de racismo (DOVIDIO; GAERTNER, 1998; GAERTNER; DOVIDIO, 1986; MCCONAHAY; HARDEE; BATTS, 1981).

Devido à recorrência dessas novas formas de expressão do preconceito, pesquisas realizadas com crianças buscaram identificar em que momento elas passam a internalizar as normas sociais que desaprovam sua manifestação explícita. Em estudo realizado em Portugal e no Brasil, França e Monteiro (2004) encontraram que crianças de 5 a 7 anos 
de idade não sofrem interferência de uma norma social antirracista na tomada de decisão por uma conduta racista, enquanto que as crianças mais velhas, entre 8 a 10 anos, são influenciadas a mascarar expressões de racismo intencionais em função da saliência da mesma norma. As autoras defendem que a responsável direta pelas mudanças nas formas de expressão do racismo parece ser a aprendizagem das normas sociais e a capacidade de agir a partir das informações fornecidas pelo contexto.

No estudo de Fernandes, Almeida e Nascimento (2008), realizado em uma cidade do interior de Sergipe, com crianças entre 5 e 8 anos, os resultados apontaram que os participantes demonstraram um alto índice de favoritismo ao alvo branco e rejeitaram o alvo negro diante de traços e conteúdos relacionados a cinco domínios: atratividade física, nível socioeconômico, inteligência, contato e proximidade. O estudo apontou, ainda, que independente da faixa etária houve uma possível demonstração de racismo nos discursos das crianças. Mais especificamente, demonstrou-se que o aumento da idade instaura um aumento do índice de rejeição ao exogrupo e identificação com o próprio grupo.

No entanto, alguns estudos demonstraram que crianças com elevados níveis de educação multicultural apresentaram menos preconceito contra grupos étnicos diferentes. Esse tipo de intervenção desestimula a exclusão social, ao investir na criação de uma norma inclusiva no grupo (VERKUYTEN, 2008; VERKUYTEN; THIJS, 2013).

Segundo Fazzi (2006), é primordial compreender como o preconceito racial se constitui e se estabelece, considerando o modo como as crianças agem, vivenciam suas relações e a forma como aprendem o significado de pertencer a uma categoria racial ou outra, internalizando o conceito de raça. A discussão a respeito da moralidade e julgamento moral se mostra relevante, tendo em vista que a primeira está relacionada com os valores que são transmitidos a partir da cultura e com a consciência que os indivíduos adquirem das regras, normas e expectativas sociais. A moralidade reflete as normas e princípios sociais, que apresentam caráter normativo e prescritivo, tendo em vista que servem para orientar a conduta dos indivíduos ao longo do desenvolvimento (LOURENÇO, 2006).

\section{JULGAMENTO MORAL}

O julgamento moral pode ser considerado como um elemento cognitivo do desenvolvimento da moralidade. É a capacidade desenvolvida pela criança de considerar uma ação como certa ou errada. Portanto, as pesquisas que discutem o julgamento moral investigam o desenvolvimento da habilidade de atribuir juízos de valor ao decorrer de todo o desenvolvimento do sujeito (MONTE, 2012).

Os experimentos realizados por Piaget (1932/1994) apontam que o raciocínio moral passa por transformações e se desenvolve no decorrer 
da infância e da adolescência. O autor constatou que crianças mais novas apresentam comportamentos heterônomos quando se deparam com questões morais, considerando que o fundamento da moralidade estava baseado no respeito unilateral às regras determinadas por figuras de autoridade. Posteriormente, na moral autônoma, a capacidade de raciocínio lógico e reversível possibilita que o indivíduo tome consciência sobre o modo como as regras são construídas e sobre a possibilidade de mudá-las. Oportuniza-se uma condição de socialização que, por meio da cooperação, da possibilidade de discutir a moral de seu grupo, desenvolve certa autonomia, uma consciência, e passa a regular-se livremente.

Mesmo considerando que o desenvolvimento da moralidade tende a ocorrer de modo paralelo à cognição e à afetividade, Piaget (1932/1994) afirma que o desenvolvimento moral não ocorre a partir de estágios propriamente ditos, tendo em vista as consideráveis variações entre as dimensões da moral e entre os valores de diferentes culturas, além de que, em alguns pontos, os julgamentos heterônomos prevalecem, ainda que em sujeitos adultos. Portanto, Piaget conclui que o mais coerente seria tratar de diferentes fases de heteronomia e autonomia ao longo da vida, considerando os diversos contextos onde a investigação ocorrer.

O psicólogo americano Lawrence Kohlberg (1964, 1976, 1992) elaborou uma tipologia onde se organizam três grandes níveis morais, cada um deles composto por dois estágios, considerando que o desenvolvimento da moralidade acontece a partir de estágios sequenciais que se organizam hierarquicamente. Assim como Piaget, o autor aponta que o desenvolvimento da moralidade está relacionado, principalmente, ao desenvolvimento cognitivo e afetivo e às interações sociais que ocorrem ao longo da vida.

Os estudos de Kohlberg sobre julgamento e o raciocínio moral demonstraram que há uma correlação entre os níveis de julgamento moral e o comportamento moral. Dessa forma, sujeitos que se encontram nos níveis mais altos de desenvolvimento possuem tendência a apresentar melhor comportamento moral do que os sujeitos que se encontrem em níveis mais baixos. Os resultados de sua pesquisa permitiram concluir que o julgamento moral de nível mais elevado consistiria em uma condição necessária, porém, não suficiente para o melhor desempenho da conduta moral (FINI, 1991).

Em uma análise sobre a gênese da generosidade na moralidade, La Taille (2006) evidenciou que a generosidade se apresenta como uma virtude presente no início da gênese da moralidade, sendo melhor assimilada e, portanto, melhor integrada à consciência moral do que a justiça nesse mesmo período do desenvolvimento. A generosidade apresenta aspectos que a tornam singular em relação à justiça. O primeiro deles é o altruísmo: no ato generoso, outra pessoa irá ser beneficiada por meio daquela ação. O segundo aspecto considera que a generosidade 
demanda uma espécie de sacrifício. Por fim, um terceiro aspecto da generosidade aponta que é dado ao outro algo que não o que lhe cabe de direito, mas que atende a uma necessidade em particular. Afirma-se que a generosidade é uma virtude que pertence ao campo moral.

De acordo com Eisenberg (1993), a generosidade atua no desenvolvimento moral, uma vez que, nas regras morais que os adultos aplicam às crianças, deixam em segundo plano as atitudes pró-sociais. Desse modo, tais atitudes, dentre elas a generosidade, devem ser mais espontâneas e autônomas nas crianças menores, pois se apresentam menos relacionadas com as ordens provenientes de autoridade.

La Taille (2006) aponta para a questão sobre a origem precoce da importância atribuída às condutas pró-sociais, assim como a relativa independência que apresenta em relação à autoridade. Alguns autores apontam que a resposta pode ser encontrada na capacidade de simpatia (ou empatia) (HOFFMAN, 1978; LENNON; EISENBERG, 1987).

\section{EMPATIA}

Pavarino, Del Prette e Del Prette (2005) definem a empatia como o potencial de aprender sentimentos e identificar-se com a situação do outro, expressando essas características por meio de ações. Além disso, possui três aspectos básicos: cognitivo, afetivo e comportamental, sendo uma subclasse das habilidades sociais.

O indivíduo é propenso, a partir do nascimento, a manifestar sinais socioemocionais, assim como responder aos sinais dos outros, de maneira que sua sobrevivência possa ser garantida por esse comportamento, que se desenvolve no decorrer de sua existência (BRAZELTON, 1994; HOPS, 1983; NOVAK, 1996; THOMPSON, 1987).

Considerando que há um aumento nos níveis de empatia à medida que os sujeitos vão se desenvolvendo (CAMINO; CAMINO; LEYENS, 1996), é importante estimulá-la. As habilidades sociais, inclusive a obtenção e o aprimoramento dos comportamentos empáticos, podem ser desenvolvidas nos primeiros ambientes onde os indivíduos interagem, como é o caso da família e da escola. Se esses comportamentos não são apresentados pelas crianças em tais ambientes, podem ser consideradas duas possibilidades: elas não possuem essas habilidades em seu repertório ou esses ambientes apresentam pouca, ou nenhuma, demanda para tais comportamentos (PAVARINO et al., 2005).

Hoffman $(1987,1991)$ destaca que o desenvolvimento da empatia apresenta um impacto sobre o julgamento e comportamento morais. Segundo esse autor, a empatia se refere a uma experiência vicária, onde o sujeito irá vivenciar uma resposta afetiva que é mais apropriada a outra pessoa do que a ele próprio. O sujeito observador tem estados 
afetivos semelhantes despertados quando entende que a outra pessoa experiencia algo negativo, doloroso ou se encontra em perigo iminente.

Apesar de considerar que a empatia é um elemento determinante na constituição da moralidade, Hoffman $(1987,1991)$ também destaca a importância da cognição para o desenvolvimento moral. Para esse autor, a partir da evolução na prática de tomada de perspectiva e concepção das representações mentais, os indivíduos passaram a desenvolver a empatia com pessoas distantes, espacialmente ou temporalmente, conseguindo aplicar a elas julgamentos morais que são aplicados a pessoas que se encontram mais próximas. Além disso, a empatia se mostra importante na internalização e adoção de princípios morais nas situações onde diferentes cursos de ação são possíveis e dilemas morais se estabelecem.

Os estudos sobre a moralidade apontam para a contribuição deste elemento para a explicação tanto de comportamentos socialmente aceitáveis, quanto de comportamentos delitivos ou transgressores (FORMIGA, 2012). Algumas relações entre empatia, moralidade e comportamentos pró-sociais puderam ser identificadas nos estudos de Garaigordobil e Galdeano (2006). Os autores tiveram como objetivo analisar as relações entre empatia e comportamento social, autoconceito, estabilidade emocional, estratégias de interação social, capacidade de analisar emoções, inteligência e criatividade. Além disso, buscaram identificar variáveis preditivas de empatia. A amostra foi constituída por 139 participantes com idade entre 10 e 12 anos. Os resultados apontaram que os participantes com empatia elevada apresentaram diversos comportamentos sociais positivos (pró-social, assertividade, autocontrole, liderança), poucos comportamentos sociais negativos (passividade, agressividade, antissocial) e muitas estratégias assertivas de interação social. Como variáveis preditivas de empatia, foram identificados: alto nível de comportamento pró-social, baixo nível de comportamento agressivo e alto autoconceito.

De modo semelhante, os achados de Findlay, Girardi e Coplan (2006), em que 136 crianças do jardim de infância e primeira série participaram do estudo, indicam que as crianças mais empáticas apresentavam maior comportamento pró-social e menos agressão e retração social. Além disso, as crianças empáticas demonstraram uma compreensão mais sofisticada da timidez e da agressão em comparação com os pares menos empáticos. Estes resultados sugerem que as crianças empáticas são mais socialmente sensíveis, tanto em termos de sua compreensão social dos outros, bem como seus próprios comportamentos sociais.

No que se refere às relações raciais, notadamente, essa capacidade de empatia se apresenta enfraquecida. A intolerância perante as diferenças é vista como uma maneira de violação dos princípios morais que envolvem o bem-estar, igualdade e justiça. Portanto, a intolerância 
é inversamente correlacionada ao julgamento moral pró-social e à empatia (MARTINS, 2013).

Nesdale, Griffith, Durkin e Maass (2005) apontam, a partir de seus estudos com crianças entre 5 e 12 anos de idade, que a empatia não se apresentou relacionada ao gosto das crianças para o mesmo grupo étnico, mas que o gosto pelo grupo étnico diferente aumentou quando os índices de empatia aumentaram. Resultado semelhante ao encontrado por Micó-Cebrián e Cava (2014), onde foram constatados maiores índices de empatia emocional em crianças com maior sensibilidade intercultural.

Com base nessas considerações - e tendo em vista que grande parte dos estudos que contemplam análises das novas formas de expressão do preconceito é realizada com sujeitos adultos, havendo uma demanda de mais análises sobre o preconceito na infância (FRANÇA; MONTEIRO, 2004) - o objetivo geral do presente estudo foi o de investigar as correlações entre julgamento moral, empatia e racismo, em crianças de 7 a 12 anos de idade. Mais especificamente, objetivou-se analisar o julgamento moral em crianças; analisar a empatia em crianças e, por fim, analisar de que maneira as crianças julgam o racismo.

\section{MÉTODO}

\section{AMOSTRA}

O estudo contou com uma amostra de 76 crianças (sendo 55,3\% meninas e 44,7\% meninos), entre 7 e 12 anos de idade ( $M=9,71 ; \mathrm{DP}=1,65)$. Dessas, 47,3\% ( $n=36)$ foram categorizadas como brancas e 52,7 \% ( $\mathrm{n}=40)$, como negras. As crianças eram estudantes do ensino fundamental I e II entre o $2^{\circ}$ e $7^{\circ}$ ano - de duas escolas particulares da cidade de Maceió (AL). A participação se deu de forma voluntária, a partir das autorizações dos pais ou responsáveis pelas crianças - mediante as assinaturas dos Termos de Consentimento Livre e Esclarecido (TCLE) - e da aceitação das crianças em participarem do estudo, assinando o termo de assentimento.

\section{INSTRUMENTOS E PROCEDIMENTOS DE COLETA DE DADOS}

As crianças responderam individualmente aos instrumentos nas dependências da escola, contando com a ajuda de uma das pesquisadoras para realizar a leitura do material e esclarecer dúvidas. Para analisar as relações estabelecidas entre julgamento moral, empatia e racismo, foram utilizados três instrumentos.

O primeiro instrumento, para análise do julgamento moral, foi adaptado do estudo de Kawashima e Martins (2013), consistindo em uma história-estímulo no formato de dilema moral, em que a protagonista teria que decidir entre agir com justiça ou com generosidade. Esse dilema apresenta como objetivo investigar se a generosidade, quando posta 
lado a lado com a justiça, é valorizada. O mesmo dilema foi apresentado aos participantes com dois desfechos diferentes (formato A - generosidade; formato B - justiça). Em seguida, os participantes foram convidados a julgar a tomada de decisão da personagem, considerando dois critérios: o quanto julgam correta e o quanto julgam justa. Foi utilizada uma escala tipo likert de 5 pontos (variando de 1 - totalmente incorreta/ totalmente injusta a 5 - totalmente correta/totalmente justa). O dilema apresentado aos participantes consistiu em:

\section{Formato A: Generosidade}

Houve um concurso na escola que elegeria o desenho mais bonito. A criança ganhadora receberia um prêmio. 0 desenho mais bonito foi o do André, mas a professora sabia que havia outro menino, o Júlio, que tinha perdido o cachorrinho na semana passada. Júlio estava muito triste e a professora ficou em dúvida se deveria dar o prêmio a André ou a Júlio. Ela resolveu dar o prêmio a Júlio.

Formato B: Justiça

Houve um concurso na escola que elegeria o desenho mais bonito. A criança ganhadora receberia um prêmio. 0 desenho mais bonito foi o do André, mas a professora sabia que havia um outro menino, o Júlio, que tinha perdido o cachorrinho na semana passada. Júlio estava muito triste e a professora ficou em dúvida se deveria dar o prêmio a André ou a Júlio. Ela resolveu dar o prêmio a André.

O instrumento para análise da empatia foi a Escala de Empatia para Crianças e Adolescentes (EECA), desenvolvida por Bryant (1982), que possui 22 itens para serem respondidos entre sim ou não. A fim de contemplar os objetivos do estudo, adaptou-se o instrumento para contar com respostas tipo likert (variando de 1 a 5). A EECA utilizada foi uma validação realizada por Koller, Camino e Ribeiro (2001).

Por fim, para analisar de que forma as crianças julgam o racismo, foi utilizado o Survey Instrument for Measuring Judgments about Emotions about Exclusion (MALTI; KILLEN; GASSER, 2009), validado para o português por Martins (2013). O instrumento consta de três situações que apresentam o contexto de exclusão, sendo duas delas relacionadas à etnia e uma relacionada ao gênero. Nesta pesquisa utilizamos uma adaptação da primeira história, uma vez que apenas esta aborda o racismo.

Após a leitura e compreensão da mesma, foi solicitado aos participantes que realizassem avaliações do ocorrido, indicando o quão correta foi a ação mencionada, respondida em uma escala tipo likert de 5 pontos (variando de 1 - totalmente errada a 5 - totalmente certa). Os participantes também tiveram que atribuir emoções ao personagem excludente (como é que Miguel vai se sentir quando excluir Bruno?), e ao personagem excluído (como é que Bruno vai se sentir quando não for 
convidado para assistir ao jogo?). Foi utilizada uma escala tipo likert de 5 pontos (variando de 1 - muito mal a 5 - muito bem). A situação apresentada aos participantes consistiu em:

Miguel e seus colegas (crianças brancas) de turma estavam muito felizes, pois tinham recebido ingressos para irem assistir a um jogo de futebol. Carlos (um menino branco) e Bruno (um menino negro), também alunos, queriam muito assistir ao jogo. Ambos gostam muito de futebol. Mas apenas existe mais um ingresso para o jogo. Miguel e seus colegas resolveram convidar Carlos porque queriam que o grupo que ia ao jogo apenas tivesse crianças parecidas com eles.

Utilizaram-se recursos imagéticos para auxiliar na elucidação racial do dilema, através de fotos de crianças (branca, negra e parda) validadas por França e Monteiro (2004). Além disso, para classificação realizada pelos pesquisadores acerca da cor da pele, fez-se uso de uma escala de cor, que variava entre 7 tons, dos quais de 5 a 7 eram considerados negros. A classificação da cor da pele era definida consensualmente tanto pelo pesquisador que estava conduzindo a aplicação quanto por seu auxiliar.

\section{PROCEDIMENTOS DE ANÁLISE DE DADOS}

Os dados foram analisados por meio do software Statistical Package for Social Science (SPSS, versão 21). Para as variáveis envolvidas foram realizadas técnicas de estatística descritiva e uma análise de correlação de Pearson (r), com o objetivo de verificar as relações existentes entre julgamento moral, racismo e empatia. O grau de significância adotado foi de $\mathrm{p} \leq 0,05$ (menor ou igual a) e a margem de confiança foi de $95 \%$.

\section{RESULTADOS}

Para avaliar a adesão dos participantes aos construtos, consideraram-se as médias dos instrumentos utilizados (Tabela 1). A ECCA apresenta dois fatores de empatia, que consistem em: empatia relacionada à tristeza pela condição de necessidade do outro e empatia por não apresentar hostilidade para com o outro, em situações nas quais isso poderia ocorrer. Foram obtidos maiores índices quando a empatia estava relacionada à tristeza pela condição de necessidade do outro, como, por exemplo, um colega de escola não ter com quem brincar.

Os resultados apresentaram, ainda, maior adesão das crianças à generosidade em detrimento da justiça e baixa adesão ao racismo. Sendo assim, as crianças aderiram mais à decisão da personagem principal (a professora) que foi baseada na generosidade (premiar a criança que estava triste porque perdeu o seu cachorro) do que a decisão que foi baseada na justiça (premiar a criança que fez o desenho mais bonito). 
Evidencia-se que as crianças tenderam a avaliar como injusta e incorreta a discriminação (a decisão do personagem dono do ingresso de não convidar o menino negro ao jogo de futebol) e a inferir a experimentação de sentimentos negativos tanto por parte da criança discriminada como por parte da criança que discriminou.

TABELA 1

MÉDIAS E DESVIOS-PADRÃO PARA JULGAMENTO MORAL, RACISMO E EMPATIA

\begin{tabular}{l|c|c}
\hline & MÉDIA & DESVIO-PADRÃO \\
\hline Generosidade & $\mathbf{4 , 0 0}$ & 1,45 \\
\hline Justiça & 3,21 & 1,53 \\
\hline Fator 1 Empatia & $\mathbf{3 , 9 2}$ & 0,80 \\
\hline Fator 2 Empatia & $\mathbf{3 , 4 8}$ & 0,74 \\
\hline Racismo & $\mathbf{1 , 9 0}$ & 1,40 \\
\hline Racismo & $\mathbf{2 , 0 5}$ & 1,35 \\
\hline Racismo & $\mathbf{1 , 5 9}$ & 1,17 \\
\hline
\end{tabular}

Fonte: elaborada pelas autoras.

Constatou-se correlação inversa entre generosidade e justiça, componentes do julgamento moral ( $r=-, 609$; $\mathrm{p} \leq 0,05)$. Desse modo, quanto mais as crianças avaliaram como correta a decisão no dilema moral que foi baseada na generosidade, menos aderiram à decisão que foi baseada na justiça. O fator de empatia por não hostilizar o outro também se mostrou inversamente correlacionado com um dos componentes de racismo - mais precisamente, com os resultados obtidos a partir da pergunta: o quão correta foi a ação mencionada na história? - ( $r=-, 347$; $\mathrm{p} \leq 0,05)$. Portanto, quanto mais as crianças consideraram incorreta a manifestação de racismo, mais aderiram à empatia. Não foram encontradas correlações entre as variáveis julgamento moral e racismo, assim como não houve correlação entre julgamento moral e empatia, como pode ser visto na Tabela 2 .

TABELA 2

COEFICIENTES DE CORRELAÇÃO R DE PEARSON PARA JULGAMENTO MORAL, RACISMO E EMPATIA

\begin{tabular}{l|c|c|c|c}
\hline & GENEROSIDADE & JUSTIÇA & $\begin{array}{c}\text { FATOR 1 } \\
\text { EMPATIA }\end{array}$ & $\begin{array}{c}\text { FATOR 2 } \\
\text { EMPATIA }\end{array}$ \\
\hline Justiça &,$- 60 *^{*}$ & - &,- 065 &, 081 \\
\hline Fator 1 Empatia &, 045 &,- 065 & - &,- 010 \\
\hline Fator 2 Empatia &,- 131 &, 081 &,- 010 & - \\
\hline Racismo &, 170 &,- 152 &,- 147 &,$- 347^{*}$ \\
\hline Racismo &,- 034 &, 033 &,- 022 &,- 064 \\
\hline Racismo &, 060 &,- 041 &,- 028 &,- 092 \\
\hline
\end{tabular}

Nota: ${ }^{*} p \leq 0,05$

Fonte: Elaborada pelas autoras. 


\section{DISCUSSÃO}

Os resultados encontrados a partir do dilema moral indicam que as crianças aderiram mais à generosidade do que à justiça, ou seja, buscaram melhorar a condição emocional do colega que está triste por perder o cachorro. Hoffman (1991) aponta que ao longo da infância a criança começa a transformar um sentimento chamado de angústia empática - quando mais nova - em angústia simpática - quando mais velha. Em linhas gerais, na angústia empática ainda não há uma distinção cognitiva entre o self e o outro, por isso, a criança vê o que está se passando com a outra pessoa e sofre como se aquilo estivesse ocorrendo com ela mesma, por isso, aliviar a dor do outro seria aliviar sua própria dor. Na angústia simpática, essa diferenciação passa a ser mais clara e a criança começa a compreender que a experiência do outro não é idêntica à sua, o que gera a necessidade de eliminar não somente a sua angústia, mas, especialmente, gera o desejo de ajudar o outro.

De modo geral, considerando os dois fatores que formam a escala de empatia, as crianças demonstraram-se empáticas em ambas as dimensões: não apenas por se entristecerem com situações de desvantagem de outra criança (Fator 1), mas também por não apresentarem hostilidade para com o outro, em situações nas quais isso poderia ocorrer (Fator 2). Considerando a faixa etária dos sujeitos participantes do presente estudo $(M=9,71)$, esses resultados se assemelham aos achados do estudo realizado por Camino et al. (1996), onde crianças com idades entre 5 e 7 anos obtiveram escores de empatia inferiores aos de crianças entre 8 e 10 anos. Ou seja, haveria um aumento nos níveis de empatia à medida que os sujeitos vão se desenvolvendo. Os autores salientam ainda que isso poderia estar relacionado ao fato de que a empatia está relacionada com a aprendizagem do que é socialmente valorizado.

A partir dos resultados obtidos, evidencia-se que os sujeitos se mostraram empáticos e com baixa adesão ao racismo, apresentando correlação negativa entre esses construtos. Quanto a isso, é importante considerar que a maioria dos sujeitos eram meninas. O estudo de Micó-Cebrián e Cava (2014) corrobora esse achado. Os autores contaram com a participação de 473 estudantes, entre 10 e 13 anos de idade ( $M=10,79)$, a fim de analisar as relações entre sensibilidade intercultural, empatia, autoconceito e satisfação com a vida. Os resultados indicaram maior sensibilidade intercultural, empatia emocional e autoconceito acadêmico em meninas em relação aos meninos, e níveis mais elevados de empatia emocional, autoconceito social e satisfação com a vida em alunos com maior sensibilidade intercultural.

De modo semelhante, Nesdale et al. (2005) examinaram o impacto da empatia nas atitudes étnicas de crianças anglo-australianas brancas, em uma amostra composta por 150 sujeitos entre 5 e 12 anos de idade. Foram avaliadas a empatia e as atitudes em relação a um mesmo 
grupo étnico (anglo-australiano) versus um grupo de etnia diferente (insulares do Pacífico). Os resultados mostraram que o gosto pelo grupo étnico diferente aumentou quando os índices de empatia eram maiores. Os autores destacam que tais discussões e achados podem contribuir para promoção de atitudes positivas das crianças em relação aos grupos étnicos minoritários.

Quanto ao racismo, este não apresentou correlações com o julgamento moral. No entanto, destaca-se que os sujeitos não se mostraram racistas em suas avaliações. Uma justificativa para esse resultado seria a de que mais da metade da amostra é composta por crianças negras. No entanto, faz-se necessário incluir no estudo uma autocategorização quanto à cor da pele. Desse modo, a partir da classificação de cada criança sobre sua cor, seria possível construir uma avaliação mais completa.

Estudos apontam que crianças com níveis mais elevados de educação multicultural em sala de aula demonstram menos preconceito entre grupos étnicos (VERKUYTEN; THIJS, 2013). Verkuyten (2008) afirma que intervenções em sala de aula, como professores que abordam exemplos de exclusão étnica e discutem a necessidade de justiça para com todas as culturas, colaboram para estabelecimento de uma norma inclusiva no grupo, desestimulando a exclusão social. Assim como aspectos mais formais da educação multicultural, por exemplo, ensinar as crianças sobre as tradições culturais de diferentes grupos étnicos, agem de modo a limitar as atitudes negativas, melhorando o conhecimento e a compreensão das crianças.

Rutland e Killen (2015) destacam que adultos e crianças são tanto os receptores quanto os autores de preconceitos. Sendo assim, é de suma importância determinar quais fatores atuam na inibição ou redução dos resultados negativos do preconceito e da exclusão. Crianças pequenas estão cientes das diferenças intergrupais e exogrupais desde muito cedo, mas o que se torna preconceito de pleno direito, de fato, emerge lentamente durante a infância e adolescência. Neste mesmo período de tempo, emergem outras questões como moralidade, uma compreensão de justiça e igualdade.

\section{CONSIDERAÇÕES FINAIS}

Embora os resultados encontrados não tenham apresentado correlações entre alguns dos construtos investigados, os objetivos do estudo foram contemplados. As correlações inversas entre generosidade e justiça, assim como entre empatia por não hostilizar o outro e racismo, bem como os índices consideráveis na escala de empatia e as médias dos instrumentos, corroboram com a ideia de que a idade de fato é um dado relevante ao considerar analisar tais construtos. A faixa etária contemplada no presente estudo $(M=9,71)$ representa uma fase no desenvolvimento 
infantil que é mais empática e voltada às necessidades dos outros devido ao amadurecimento cognitivo, ou que desenvolve o comportamento empático devido ao desejo que surge de demonstrarem ser socialmente corretos (HOFFMAN, 1991).

Mesmo considerando as contribuições das discussões realizadas, algumas limitações podem ser destacadas. Trata-se de uma amostra pequena e, desse modo, com generalização ainda limitada. É possível que as correlações entre os demais construtos pudessem ter sido mais bem avaliadas em amostras mais abrangentes.

Além disso, considerando que os sujeitos do presente estudo não aderiram ao racismo, ao contrário do que é apontado na literatura (FERNANDES et al., 2008; FRANÇA; MONTEIRO, 2004), pesquisas futuras poderiam considerar outros contextos, podendo trazer novas contribuições para o tema. Por exemplo, o papel da escola nas relações infantis e como de fato tal ambiente tem influenciado nas descobertas sobre o tema. Considerando os achados de Verkuyten (2008), intervenções realizadas em sala de aula atuam de modo positivo na diminuição do preconceito. Portanto, poderiam ser analisadas situações cotidianas do ambiente escolar, como a sala de aula e recreio.

Segundo Menezes (2003), a escola apresenta responsabilidade no processo de socialização infantil, instituindo relações entre crianças de diversos núcleos familiares. Essa interação diversificada pode fazer com que a escola se torne o primeiro lugar de experiência de conflitos raciais. Portanto, levando em consideração o papel da escola na socialização infantil, por esta ser um ambiente que permite a convivência entre crianças com diversas características (raça, gênero, idade, classe social), pode-se pensar em uma possível influência do ambiente escolar sobre as relações inter-raciais infantis, a expressão do preconceito, da moralidade e da empatia.

Por fim, ao considerar as relações sociais infantis, pode-se pensar no papel que a família exerce sobre estas, bem como analisar outras questões, como os comportamentos antissociais e a agressividade, que podem ter relação com a empatia e tolerância à diversidade, permeando o curso do desenvolvimento infantil e auxiliando no entendimento do preconceito racial na infância.

\section{REFERÊNCIAS}

ABOUD, Frances. Children \& prejudice. Oxford: Basil Blackwell, 1988.

ALLPORT, Gordon Willard. The Nature of Prejudice. Cambridge: Addison-Wesley, 1954.

BRAZELTON, Thomas Berry. Momentos decisivos do desenvolvimento infantil. São Paulo: Martins Fontes, 1994.

BRYANT, Brenda K. An index of empathy for children and adolescents. Child development, v. 53, n. 2, p. 413-425, 1982. DOI:10.2307/1128984 
CAMINO, Cleonice; CAMINO, Leoncio; LEYENS, Jacques-Philippe. Julgamento moral, emoção e empatia. In: TRINDADE, Zeidi Araujo; CAMINO, Cleonice (Org.). Cognição social e juízo moral. Rio de Janeiro: Coletâneas da ANPEPP, 1996. p. 109-135.

CAMINO, Leoncio et al. A face oculta do racismo no Brasil: uma análise psicossociológica. Revista Psicologia Política, n. 1, p. 13-36, 2001. Disponível: http://each.uspnet.usp.br/rpp/index. php/RPPEACH/article/view/1/1. Acesso em: fev. 2017.

DOVIDIO, John F.; GAERTNER, Samuel L. On the nature of contemporary prejudice: the causes, consequences and challenges of Aversive Racism. In: EBERHARDT, Jennifer Lynn; FISKE, Susan Tufts (Ed.). Confronting Racism: the problem and the responses. California: Sage, 1998. p. 3-32.

DOYLE, Anna Beth; ABOUD, Frances E. A. longitudinal study of white children's racial prejudice as a social-cognitive development. Merrill-Palmer Quarterly, v. 41, n. 2, p. 210-229, 1995. Disponível em: <https://www.jstor.org/stable/23090532?seq=1\#page_scan_tab_contents> Acesso em: fev. 2017.

EISENBERG, Nancy. Comunicação pessoal. Tempe, Arizona, 1993.

FAZZI, Rita de Cássia. O drama racial de crianças brasileiras: socialização entre pares e preconceitos. Belo Horizonte: Autêntica, 2006.

FERNANDES, Sheyla Christine Santos. Crenças raciais e infra-humanização: uma análise psicossocial do preconceito contra negros. 2011. Tese (Doutorado em Psicologia Social) Universidade Federal da Bahia, Salvador, 2011.

FERNANDES, Sheyla Christine Santos; ALMEIDA, Saulo Santos Menezes; NASCIMENTO, Conceição Bruna Soares. Análise do preconceito racial em uma amostra de crianças brancas de 5 a 8 anos de idade. Psico, v. 39, n. 4, p. 441-447, out./dez. 2008. Disponível em: <http:// revistaseletronicas.pucrs.br/ojs/index.php/revistapsico/article/view/1451> Acesso em: ago. 2016.

FINDLAY, Leanne C.; GIRARDI, Alberta; COPLAN, Robert J. Links between empathy, social behavior, and social understanding in early childhood. Early Childhood Research Quarterly, v. 21, n. 3, p. 347-359, 2006. DOI: https://doi.org/10.1016/j.ecresq.2006.07.009

FINI, Lucila Diehl Tolaine. Desenvolvimento moral: de Piaget a Kohlberg. Perspectiva, v. 9, n. 16, p. 58-78, 1991. Disponível em: <https://periodicos.ufsc.br/index.php/perspectiva/article/ viewFile/9127/10679> Acesso em: fev. 2017.

FORMIGA, Nilton Soares. Os estudos sobre empatia: Reflexões sobre um construto psicológico em diversas áreas científicas. Revista eletrônica psicologia.com.pt, n. 1, p. 1-25, 2012. Disponível em: <http://www.psicologia.pt/artigos/textos/A0639.pdf> Acesso em: fev. 2017.

FRANÇA, Dalila Xavier; MONTEIRO, Maria Benedicta. A expressão das formas indirectas de racismo na infância. Análise Psicológica, v. 22, n. 4, p. 705-720, 2004. Disponível em: <http:// www.scielo.mec.pt/scielo.php?script=sci_arttext\&pid=S0870-82312004000400006>. Acesso em: ago. 2016.

GAERTNER, Samuel. L.; DOVIDIO, John. F. The aversive form of racism. In: DOVIDIO, J. F; GAERTNER, S. L. (Ed.). Prejudice, discrimination, and racism: theory and research. Orlando: Academic Press, 1986. p. 61-89.

GARAIGORDOBIL, Maite; GALDEANO, Patrícia Garcia de. Empathy in children aged 10 to 12 years. Psicothema, v. 18, n. 2, p. 180-186, 2006. Disponível em: <http://europepmc.org/abstract/ med/17296029> Acesso em: fev. 2017.

HOFFMAN, Martin L. Desenvolvimento moral. In: MUSSEN, Paul (Ed.). Psicologia da criança: socialização. São Paulo: Edusp, 1978. p. 1170. (Carmichael).

HOFFMAN, Martin L. The contribution of empathy to justice and moral judgment. In: EISENBERG, Nancy; STRAYER, Janet (Ed.). Empathy and its development. New York: Cambridge University Press, 1987. p. 47-79.

HOFFMAN, Martin L. Empathy, social cognition and moral action. In: KURTINES, W. M.; GEWIRTZ, Jacob L. (Ed.). Handbook of moral behavior and development. New Jersey: LEA, 1991. p. 65-87. 
HOPS, Hyman. Children's social competence and skills: current research practices and future directions. Behavior Therapy, v. 14, p. 3-18, 1983. DOI: http://doi.org/10.1016/ S0005-7894(83)80084-7

KATZ, Ilan; WACKENHUT, J.; HASS, R. G. Racial ambivalence, value duality, and behavior. In: DOVIDIO, John F.; GAERTNER, Samuel L. (Ed.). Prejudice, Discrimination, and Racism. New York: Academic Press, 1986. p. 35-59.

KAWASHIMA, Rosana Akemi; MARTINS, Raul Aragão. Dilema moral na educação infantil: generosidade ou justiça? Estudos em Avaliação Educacional, São Paulo, v. 24, n. 56, p. 48-74, 2013. DOI: http://dx.doi.org/10.18222/eae245620132734

KOHLBERG, Lawrence. Development of Moral Character and Moral Ideology. In: HOFFMAN, Martin L.; HOFFMAN, Lois Wladis. Review of Child Development Research, v.1. New York: Russel Sage Foundation, 1964. p. 212-321.

KOHLBERG, Lawrence. Moral stage and moralization: The cognitive developmental approach to socialization. In: GOSLIN, David (Org.). Handbook of socialization theory and research. Chicago: Rand McNally, 1976. p. 325-480.

KOHLBERG, Lawrence. Psicologia del desarrollo moral. Bilbao, Espanha: Desclée de Brower, 1992.

KOLLER, Ś́lvia Helena; CAMINO, Cleonice; RIBEIRO, J'aims. Adaptação e validação interna de duas escalas de empatia para uso no Brasil. Estudos de Psicologia, Campinas, v. 18, n. 3, p. 43-53, 2001. DOI: http://dx.doi.org/10.1590/S0103-166X2001000300004

LA TAILLE, Yves de. A importância da generosidade no início da gênese da moralidade na criança. Psicologia: Reflexão e Crítica, v. 19, n. 1, p. 9-17, 2006. DOI: http://dx.doi.org/10.1590/ S0102-79722006000100003.

LENNON, Randy; EISENBERG, Nancy. Gender and age differences in empathy and sympathy. In: EISENBERG, Nancy; STRAYER, Janet (Org.). Empathy and its development. Cambridge University Press: New York, 1987. p. 195-217.

LOURENÇO, Orlando Martins. Psicologia de desenvolvimento moral: teoria, dados e implicações. 3. ed. Coimbra: Livraria Almedina, 2006.

MALTI, Tina; KILLEN, Melanie; GASSER, Luciano. Social exclusion task: judgments and emotions. Unpublished instrument, University of Zurich, 2009.

MARTINS, Marta Mendes. Exclusão étnica, julgamento moral e emoções morais: estudo em adolescentes. 2013. Dissertação (Mestrado em Psicologia da Educação) - Universidade Lusófona de Humanidades e Tecnologias, Lisboa, 2013.

MATTOS, Laura. Tô de mal. Revista da Folha de São Paulo, 2007. Disponível em: <http://www1. folha.uol.com.br/fsp/cotidian/ff2511200728.htm>. Acesso em: fev. 2017.

MCCONAHAY, John B. Modern racism, ambivalence, and the modern racism scale. In: DOVIDIO, John F.; GAERTNER, Samuel L. (Ed.). Prejudice, discrimination, and racism. San Diego, CA: Academic Press, 1986. p. 91-125.

MCCONAHAY, John B.; HARDEE, Betty B.; BATTS, Valerie. Has racism declined in America? It depends upon who is asking and what is asked. Journal of Conflict Resolution, v. 25, p. 563-579, 1981. Disponível em: http://www.jstor.org/stable/173910?origin=JSTOR-pdf\&seq=1\#page_scan_ tab_contents. Acesso em: ago. 2016.

MEERTENS, Ree; PETTIGREW, Thomas. Será o racismo sutil mesmo racismo? In: VALA, Jorge (Org.), Novos racismos: perspectivas comparativas. Oeiras: Celta, 1999. p. 11-29.

MENEZES, Waléria. O preconceito racial e suas repercussões na instituição escola. Cadernos de Estudos Sociais, v. 19, n. 1, p. 95-106, 2003. Disponível em: <https://periodicos.fundaj.gov.br/ TPD/article/download/943/664> Acesso em: fevereiro 2017.

MICÓ-CEBRIÁN, Paula; CAVA, María-Jesús. Sensibilidad intercultural, empatía, autoconcepto y satisfacción con la vida en alumnos de educación primaria. Journal Infancia y Aprendizaje, v. 37, n. 2, p. 342-367, 2014. DOI: http://dx.doi.org/10.1080/02103702.2014.918819 
MONTE, Franciela Félix de Carvalho. Valores humanos, julgamento moral, empatia e atos infracionais cometidos por adolescentes. 2012. Dissertação (Mestrado em Psicologia Cognitiva) - Universidade Federal de Pernambuco, Recife, 2012.

NESDALE, Drew; GRIFFITH, Judith; DURKIN, Kevin; MAASS, Anne. Empathy, group norms and children's ethnic attitudes. Journal of Applied Developmental Psychology, v. 26, n. 6, p. 623-637, 2005. DOI: https://doi.org/10.1016/j.appdev.2005.08.003

NOVAK, Gary. Developmental psychology: dynamical systems and behavior analysis. New York: Context Press, 1996.

PAVARINO, Michelle Girade; DEL PRETTE, Almir; DEL PRETTE, Zilda. Agressividade e empatia na infância: um estudo correlacional com pré-escolares. Interação em Psicologia, v. 9, n. 2 , p. 215-225, 2005. Disponível em: <http://pesquisa.bvs.br/brasil/resource/pt/psi-33623> Acesso em: jan. 2017.

PETTIGREW, Thomas; MEERTENS, Ree. Subtle and blatant prejudice in Western Europe. European Journal of Social Psychology, v. 25, p. 57-75, 1995. DOI: 10.1002/ejsp.2420250106

PIAGET, Jean. O juízo moral na criança. São Paulo: Summus, 1994. 1ª edição de 1932.

RODRIGUES, Iryá. Menina sofre racismo em escola do AC e não quer mais ir à aula, diz tia. G1, 2015. Disponível em: <http://g1.globo.com/ac/acre/noticia/2015/11/menina-sofre-racismo-emescola-do-ac-e-nao-quer-mais-ir-aula-diz-tia.html>. Acesso em: mar. 2017.

RUTLAND, Adam; KILLEN, Melanie. A developmental science approach to reducing prejudice and social exclusion: intergroup processes, social-cognitive development, and moral reasoning. Social Issues and Policy Review, v. 9, n. 1, p.121-154, 2015. DOI: 10.1111/sipr.12012

THOMPSON, R. A. Empathy and emotional understanding: the early development of empathy. In: EISENBERG, Nancy; STRAYER, Janet (Org.). Empathy and its development. New York: Cambridge University Press, 1987. p. 119-145.

VALA, Jorge; BRITO, Rodrigo; LOPES, Diniz. Expressões dos racismos em Portugal. Lisboa: ICS, Estudos e Investigações, 1999.

VERKUYTEN, Maykel. Multiculturalism and group evaluations among minority and majority groups. In: LEVY, Sheri; KILLEN, Melanie (Ed.). Intergroup attitudes and relations in childhood through adulthood. Oxford, U.K.: Oxford University Press, 2008. p. 157-172.

VERKUYTEN, Maykel; THIJS, Jochem. Multicultural education and inter-ethnic attitudes: an intergroup perspective. European Psychologist, v. 18, p. 179-190, 2013. DOI: 10.1027/1016-9040/ a000152. 